\title{
Modelling interception loss from evergreen oak Mediterranean savannas: Application of a tree-based modelling approach
}

\author{
F.L. Pereira ${ }^{a, e, *}$, J.H.C. Gash ${ }^{b, c}$, J.S. David ${ }^{d, e}$, T.S. David $^{f, e}$, P.R. Monteiro ${ }^{d}$, F. Valente $^{d, e}$ \\ ${ }^{a}$ Escola Superior Agrária, Instituto Politécnico de Castelo Branco, Quinta da Senhora de Mércules, 6001-909 Castelo Branco, Portugal \\ ${ }^{\mathrm{b}}$ Centre for Ecology and Hydrology, Wallingford OX108BB, United Kingdom \\ ${ }^{c}$ VU University Amsterdam, Amsterdam, $1081 \mathrm{HV}$, The Netherlands \\ dinstituto Superior de Agronomia, Universidade Técnica de Lisboa, Tapada da Ajuda, 1349-017 Lisboa, Portugal \\ e Centro de Estudos Florestais, Tapada da Ajuda, 1349-017 Lisboa, Portugal \\ ${ }^{\mathrm{f}}$ Instituto Nacional de Recursos Biológicos - INRB, I.P., Av. da República, Quinta do Marquês, 2780-159 Oeiras, Portugal
}

\section{A R T I C L E I N F O}

Article history:

Received 15 July 2008

Received in revised form

8 October 2008

Accepted 21 October 2008

Keywords:

Rainfall interception

Isolated trees

Savannas

Quercus ilex

Wet bulb temperature

Gash analytical model

\begin{abstract}
A B S T R A C T
In a previous study, it was shown that an isolated, fully saturated tree-crown behaves like a wet bulb, allowing evaporation of intercepted rainfall to be estimated by a simple diffusion equation for water vapour. This observation was taken as the basis for a new approach in modelling interception loss from savanna-type woodland, whereby the ecosystem evaporation is derived by scaling up the evaporation from individual trees, rather than by considering a homogeneous forest cover. Interception loss from isolated trees was estimated by combining the aforementioned equation for water vapour flux with Gash's analytical model. A new methodology, which avoids the subjectivity inherent in the Leyton method, was used for estimating the crown storage capacity. Modelling performance was evaluated against data from two Mediterranean savanna-type oak woodlands (montados) in southern Portugal. Interception loss estimates were in good agreement with observations in both sites. The proposed modelling approach is physically based, requires only a limited amount of data and should be suitable for the modelling of interception loss in isolated trees and savannatype ecosystems.
\end{abstract}

(c) 2008 Elsevier B.V. All rights reserved.

\section{Introduction}

Large areas of the Mediterranean climatic zone are suffering increasing demand for water, with over-extraction now threatening the survival of some important ecosystems. Sustainable water management is crucial, but this must be built on sound knowledge of the components of catchment water balance. Sparse, savanna-type forest is particularly vulnerable, making it a priority to research the water use of this vegetation type. In Portugal, savanna-type evergreen oak woodlands (montados) occupy over 1.12 Mha (DGRF, 2007). Here, grazing by animals typically creates a two component structure: grasses and small shrubs occupy a large percentage of the total area, but there are isolated trees, albeit with densities that can be as low as only 10 trees per hectare. Cork oak (Quercus suber) and holm oak (Quercus ilex) are the dominant species.

Evaporation is a major component of the montado water balance. Over a year the evaporation is mostly transpiration

\footnotetext{
* Corresponding author at: Escola Superior Agrária, Instituto Politécnico de Castelo Branco, Quinta da Senhora de Mércules, 6001-909 Castelo Branco, Portugal. Tel.: +351 272339974/963221211; fax: +351 272339901.

E-mail address: flpereira@esa.ipcb.pt (F.L. Pereira). 
(e.g. David et al., 2006), but during the winter rains, when groundwater recharge occurs, evaporation of rainfall intercepted by the trees may be a significant component. There is thus a need to model interception loss from these savannatype ecosystems. However, existing models of forest rainfall interception may not be appropriate, because they are essentially one-dimensional, and evaporation from an isolated tree is likely to be a three dimensional process. For this type of forest, it might be preferable to model evaporation from the whole forest by scaling-up the estimated evaporation from individual trees. In a previous study, Pereira et al. (2009) showed that when available energy is low (as it is during rainfall) the temperature of a saturated, isolated tree crown approaches the wet bulb temperature of the surrounding air. This allowed the evaporation rate of intercepted rainfall to be obtained using a simple Dalton-type equation which only requires knowledge of the air dry and wet bulb temperatures and of the bulk tree crown aerodynamic conductance. The use of a similar procedure, based on surface temperature, was implicitly recognized in the early work of Rutter et al. (1971), as a primary alternative for estimating the evaporation rate in wet conditions. However, most of the subsequent studies ignored this suggestion, leading to a general use of the more data-demanding onedimensional Penman-Monteith equation, which explicitly excludes surface temperature.

In this paper we present the results of an interception study in a Mediterranean savanna-type oak woodland in southern Portugal. A tree-based interception model, combining an adaptation of Gash's analytical model with the procedure proposed by Pereira et al. (2009) to evaluate average wet crown evaporation, is developed and tested against field observations.

\section{Gash's analytical model: adaptation to a tree-based approach}

By combining the conceptual framework of the Rutter model (Rutter et al., 1971) with some of the insights into the interception process first described by Horton (1919) (see also Gash and Shuttleworth, 2007), Gash (1979) derived an analytical, storm-based interception model. This model considers rainfall as a succession of separate storms, each comprising three distinct phases: the first, corresponding to the canopy wetting-up occurring from the onset of rainfall until saturation is reached; the second, corresponding to a period of complete canopy saturation; and the third, starting at the end of rainfall and lasting until the trunks and canopy are completely dry (Gash, 1979).

The model assumes that the meteorological conditions are identical for the two initial phases, represented by the average rainfall $(\bar{R})$ and evaporation $(\bar{E})$ rates for saturated conditions over the entire simulation period.

Emulating the Rutter model, the original Gash model considers the same tree structure parameters and assumes that the storages associated with the forest cover extend over the total ground area. By making this assumption the model will overestimate the interception loss in sparse forests (Gash et al., 1995; Valente et al., 1997). To overcome this, both models were reformulated (Gash et al., 1995; Valente et al., 1997) to be suitable for sparse canopies by separating the entire area into two components: the forest canopy and the open spaces between tree crowns. Since the evaporation rate from the forest component $\left(E_{c}\right)$ was considered the same as for a closed forest, the overall evaporation from the sparse forest $(E)$ was reduced in proportion to the canopy cover fraction (c), i.e. $E=c E_{c}$. The subscript $c$ will be applied hereafter to any parameter or variable that refers to the covered area. The resulting revised versions, being conceptually better, are preferable even for closed forests given that these sparse versions reduce to the original ones when the canopy cover (c) approaches unity.

The revised version of the Gash analytical model proposed by Valente et al. (1997) was used in this study. The model was applied at the tree rather than stand level, considering each single tree as a small, limited closed canopy $(c=1$, at the individual tree level). Interception loss for each individual tree was expressed on a crown projected area basis. Interception loss from the whole forest was then calculated by multiplying the single-tree evaporation (expressed in $\mathrm{mm}$, on a crownprojected area basis) by the forest crown cover fraction. This procedure is based on the assumption that both the measurements and the sampled trees are representative of the entire stand.

Although the average evaporation rate $\left(\bar{E}_{c}\right)$ from saturated canopies has been found to be a relatively conservative parameter (David et al., 2005), the success of the modelling depends on the use of a correct $\bar{E}_{c}$ value, given the high sensitivity of the Gash analytical model to changes both in this parameter (Asdak et al., 1998) and in the $\bar{E}_{c} / \bar{R}$ ratio (Schellekens et al., 1999; Sraj et al., 2008). In the present study we used the $\bar{E}_{c}$ values estimated by Pereira et al. (2009) from the wet crown surface temperature and the bulk tree crown aerodynamic conductance.

Because rainfall rate is used to determine the amount of time the canopy is saturated, all versions of the Gash analytical model are also highly sensitive to errors/variations in the mean rainfall rate $(\bar{R})$ (Asdak et al., 1998; Hutjes et al., 1990). Therefore, special care must be taken on the choice of the method used to estimate $\bar{R}$. We used the procedure originally described by Gash (1979), considering that hours when rainfall equals or exceeds a given threshold are representative of canopy saturation conditions.

Another key parameter of the model is the canopy storage capacity (S), commonly estimated by the so-called Leyton method (Leyton et al., 1967). However, this method is somewhat subjective in the selection of the storms used to derive $S$ and this may be particularly critical when throughfall is highly variable in space (Lloyd et al., 1988), as is the case under isolated trees (see David et al., 2006). Here, we estimated $S$ using a new approach, building on previous work by Lloyd et al. (1988) and corresponding to the "mean method" referred to by Klaassen et al. (1998), but accounting for evaporation during the wetting phase. The procedure (described in detail in Appendix A) uses information from a larger number of rainfall events, is less sensitive to throughfall spatial variability, and is conceptually consistent with the formulation of the Gash analytical model. 
Table 1 - Main allometric characteristics of the $Q$. ilex trees used in the interception loss measurement: diameter at breast height (DBH), tree height $(h)$, mean tree crown radius $\left(c_{r}\right)$ and tree crown projected area (CPA).

\begin{tabular}{lcccc} 
Tree no. & DBH $(\mathrm{m})$ & $h(\mathrm{~m})$ & $c_{r}(\mathrm{~m})$ & $\mathrm{CPA}\left(\mathrm{m}^{2}\right)$ \\
\hline 1 & 0.41 & 7.50 & 6.01 & 113.62 \\
2 & 0.59 & 7.50 & 6.20 & 120.62 \\
3 & 0.42 & 8.50 & 6.19 & 120.37 \\
\hline
\end{tabular}

\section{Sites and instrumentation}

The experimental work was carried out at two evergreen oak savanna-type sites (hereafter referred as Mitra I and Mitra II), both at the "Herdade da Mitra", University of Évora, Southern Portugal.

The forest at both sites share a nearly identical structure and composition, with $Q$. ilex being the dominant tree species, albeit with differences in crown cover fraction: 39\% in Mitra I (David et al., 2006) and 21\% in Mitra II (Carreiras et al., 2006). The climate is Mediterranean, with hot, dry summers and rain falling mainly between autumn and early spring. Prevailing wind directions during rainfall are between south and west, and predominant rainfall inclination (angle with the vertical) is between $26^{\circ}$ and $40^{\circ}$ (David et al., 2006).

\subsection{The Mitra II site}

Two nearby experimental plots were set up at Mitra II $\left(38^{\circ} 32^{\prime} \mathrm{N}\right.$, $\left.8^{\circ} 00^{\prime} \mathrm{W}\right)$ : a "Tree-plot" and an "Open-plot". The first was located inside the oak woodland and included nine $Q$. ilex trees. Throughfall was measured in three of these trees using a set of metal troughs, comprising four troughs per tree (the main characteristics of the studied trees are presented in Table 1). Each trough was connected to a plastic bin where the collected water was stored for later measurement. Measurements were made from July 2006 to May 2007. However, measurements were not continuous because occasional high rainfall storms caused data loss when the bins overflowed. Fig. 1 represents the throughfall measuring setup for one of the trees. The troughs were either 7.3 or $9.7 \mathrm{~m}$ long, which in all cases extended beyond the crown projected limits. Depending on their length, the troughs' collecting areas were 1.16 and $1.99 \mathrm{~m}^{2}$ respectively. Their open surface was trapezoidal shaped, with the shortest edge positioned next to the tree trunks. The troughs were installed at a height of about $0.8 \mathrm{~m}$. For each tree, the troughs were equally spaced at right angles, aligned with the NE-SW and NW-SE azimuths. Each trough was considered representative of a $90^{\circ}$ circular sector, bisected by the trough longitudinal axis and centred on the tree position (see Fig. 1).

Meteorological variables controlling evaporation were also measured in this plot, namely radiation, wind speed, dry and wet bulb temperatures, leaf temperature and leaf boundary layer conductance. Pereira et al. (2009) give a detailed description of these measurements as well as of the general characteristics of the site. Further details are also given by Pereira et al. (2007). Stemflow was not measured since it was considered negligible for this oak species: the results of David et al. (2006) showed that it only represents $0.26 \%$ of gross rainfall on a crown area basis.

The Open-plot was located in a large forest opening, about $150 \mathrm{~m}$ from the Tree-plot. Gross rainfall was measured here using three different devices: a collection gauge with a $147 \mathrm{~mm}$ diameter funnel, a 0.2-mm tipping-bucket raingauge (Casella, Bedford, UK), and a 9.7-m long trough identical to those used for throughfall monitoring but connected to an automatic siphoning gauge. Both trough and tipping-bucket measurements were totalised and stored every $10 \mathrm{~min}$ in a CR10 datalogger (Campbell Scientific, Shepshed, UK). Rainfall in the collection gauge was measured at variable time intervals, depending on rainfall occurrence.

\subsection{The Mitra I site}

The Mitra I site was located some $3 \mathrm{~km}$ away from Mitra II $\left(38^{\circ} 32^{\prime} \mathrm{N}, 8^{\circ} 01^{\prime} \mathrm{W}\right)$ and was installed for the previous study described by David et al. (2006). At this site throughfall was measured under and around one isolated Q. ilex tree through a cross-patterned array of ground-level funnel gauges. The ground-level rainfall sampling consisted of 28 gauges (8 automatic tipping-bucket raingauges plus 20 plastic collection gauges) located in a radial layout centred on the tree (at a $90^{\circ}$ separation), and extending well beyond the crown limits. Measurements were made in the north-south and east-west azimuths. Stemflow was measured using a rubber collar spiralling around the tree stem and connected to an automatic tipping-bucket recorder. Gross rainfall was measured both at

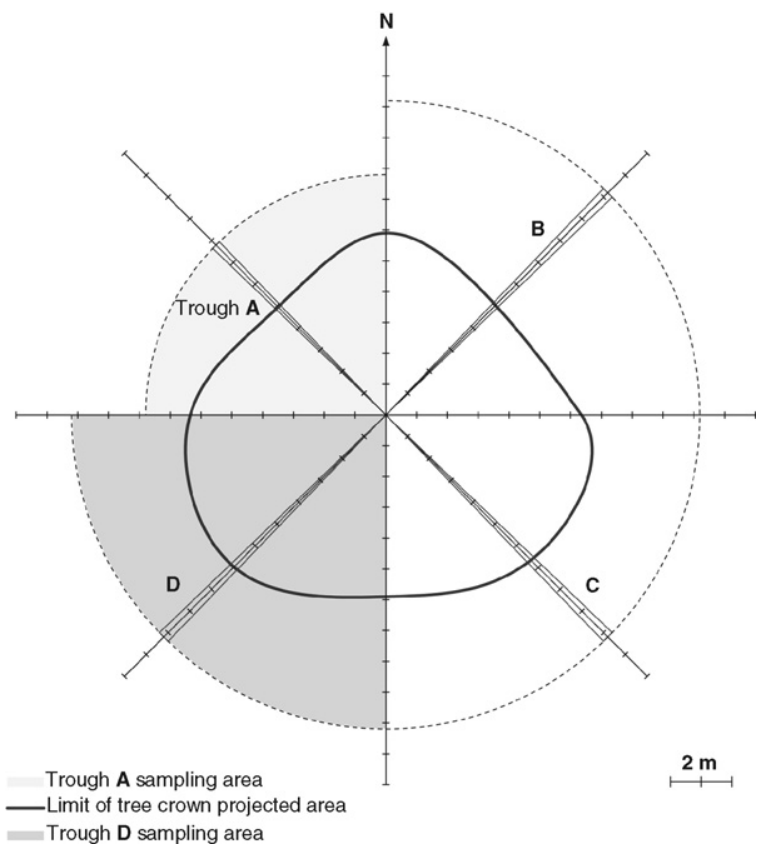

Fig. 1 - Diagram of the experimental setup used in the measurement of throughfall in Mitra II. The trough system mounted around tree no. 1 is represented, as an example. The other two monitored trees had similar systems mounted around them varying only on the total length of each trough which was dependent upon the tree crown radius. North azimuth is indicated, allowing the relative position of each trough to be easily referenced. 
the top of the tree and at ground level, while the meteorological variables controlling evaporation were monitored by an automatic weather station. Measurements made by automatic instruments were recorded by CR10 data-loggers at 10 min intervals. Measurements were taken from October 1996 to September 1998. A more detailed description of the Mitra I site and its instrumentation is given by David et al. (2006).

\section{Methods}

\subsection{Interception loss}

The procedure used to estimate interception loss (I) from the individual Q. ilex tree of Mitra I site is described in detail by David et al. (2006). The same tree-based procedure for evaluating interception loss was also used at the Mitra II site, with I being estimated for each sampled tree as the difference between the volume of rainfall that would reach the ground if the tree were not present and that actually reaching the ground. As noted by David et al. (2006), this procedure is only correct if the sampling area for each tree includes the entire ground surface where the ground-level rainfall distribution can be influenced by the presence of the tree, including the area of the downwind rain-shadow. In both sites (Mitra I and Mitra II) the size of the throughfall sampling area for each tree was big enough to accommodate the rain-shadow effect on the leeward side of the tree, up to rainfall inclinations of $40-45^{\circ}$.

In Mitra II, the volumes of rainfall that would have been collected if the trees were not there and the throughfall/ rainfall measured under the influence of the trees were calculated for each individual tree from, respectively:

(a) The gross rainfall measured by the tipping-bucket rain gauge at the Open-plot multiplied by the total tree sampling area.

(b) The sum of the volumes of water that actually falls on each of the four $90^{\circ}$ circular sampling sectors, calculated as the volume of water collected by the trough multiplied by the ratio between the area of the $90^{\circ}$ sampling sector and the collecting area of the trough (see Fig. 1).

Interception loss from a given tree was then estimated as the difference between those two volumes divided by the tree crown projected area, therefore expressed in $\mathrm{mm}$ (on a crownprojected area basis). Average tree interception loss was taken as the average of the estimates for the three sampled trees.

This procedure allowed the estimate of the equivalent throughfall $\left(T_{f, e}\right)$, i.e. the average throughfall that would occur if all the rainfall was vertical (David et al., 2006). As stressed by David et al. (2006), throughfall directly beneath the isolated crowns includes upwind rainfall concentration areas and does not take into account all the rain-shadow leeward areas, particularly those extending beyond the crown edges. Equivalent throughfall is determined as $T_{f, e}=P_{g}-I-S_{f}$ or, if stemflow is neglected, simply as $T_{f, e}=P_{g}-I$, with all the variables being expressed in $\mathrm{mm}$, on a crown-projected area basis. Although being a theoretical variable, equivalent throughfall should be used (instead of actual throughfall) in the estimation of model parameters and in the application of the model to single, isolated trees.

Since the volume of throughfall collected by the troughs in Mitra II was stored in plastic bins, interception loss was evaluated in this site periodically rather than on a rainfall event basis.

\subsection{Modelling interception loss}

The revised (sparse) version of the Gash analytical model, as adapted by Valente et al. (1997), was applied at the individual tree level on a daily basis, assuming a single storm per rainday, using data from the Mitra I and Mitra II sites. The several components of interception were calculated as indicated by Valente et al. (1997) but neglecting stemflow $\left(\mathrm{S}_{f}\right)$, which was considered negligible for $Q$. ilex as previously discussed. Model performance was evaluated simply by the error, expressed as a percentage, between the model estimates and the observed values.

\subsection{Estimation of model parameters}

When stemflow is negligible, the parameters needed for the model are the mean evaporation $\left(\bar{E}_{c}\right)$ and rainfall $(\bar{R})$ rates under canopy saturation, the crown cover fraction (c), and the canopy/crown storage capacity $\left(\mathrm{S}_{\mathrm{c}}\right)$. The crown cover fraction was assumed to be 1 at the individual crown level.

Following Gash (1979), Pereira et al. (2009) estimated $\bar{E}_{c}$ as the average evaporation rate for all hours when gross rainfall rate equalled or exceeded $0.4 \mathrm{~mm} \mathrm{~h}^{-1}$ (two bucket tips). These authors used a Dalton-type equation to estimate the average evaporation rate from a fully wet isolated crown from its surface temperature $\left(T_{s}\right)$. Two estimates were obtained for $\bar{E}_{c}$ : one assuming $T_{s}$ equal to the wet bulb temperature of the surrounding air $\left(\bar{E}_{c}\left(T_{s, w}\right)\right)$, and the other considering the additional influence of the energy input to the tree crown $\left(\bar{E}_{c}\left(T_{s, \text { calc }}\right)\right)$. In the first case, $\bar{E}_{c}$ was simply estimated from measurements of the air dry and wet bulb temperatures, windspeed and bulk crown aerodynamic conductance, whereas in the second case radiation was also taken into account (see Pereira et al., 2009). This latter approach corresponds to a combination of an equation to calculate the wet crown surface temperature $\left(T_{s, \text { calc }}\right)$ with the water vapour flux equation, which is similar to the PenmanMonteith model applied at the individual tree level (i.e., using the individual crown bulk aerodynamic conductance and meteorological variables adjacent to the tree crown).

Given the frequent malfunction of the psychrometer installed at Mitra I, $\bar{E}_{c}$ could only be determined from data obtained at the Mitra II site during 2005-2007. This parameter was also applied at Mitra I under the assumption that average meteorological and plant conditions are similar at both sites.

At Mitra II, the mean rainfall rate $(\bar{R})$ was determined from rainfall measurements made at the Open-plot for the same period when throughfall was monitored. At Mitra I, an independent estimate of $\bar{R}$ was obtained using rainfall data for the whole measuring period. In both cases, $\bar{R}$ was estimated according to same criterion used for $\bar{E}_{c}$ : i.e. the average of all hours when $P_{g}$ equalled or exceeded $0.4 \mathrm{~mm} \mathrm{~h}^{-1}$. 
The canopy storage capacity $\left(S_{c}\right)$ was determined with the equation derived in Appendix A (Eq. (A14)), using the 1996 subset of data collected by David et al. (2006) at Mitra I. Each rainday was taken as an independent storm and only storms with $P_{g} \geq 1.5 \mathrm{~mm}$ were considered, to ensure the complete saturation of the canopy.

\section{Results}

\subsection{Interception loss measurements at Mitra II}

Over the monitoring period, total gross rainfall and interception loss, expressed on a crown-projected area basis, were 528.7 and $156.7 \mathrm{~mm}$, respectively. Therefore, interception loss represented $29.6 \%$ of $P_{g}$. After scaling up these results to the entire stand area, multiplying by the montado crown cover fraction (0.21), total interception loss represented $32.9 \mathrm{~mm}$, i.e. $6.2 \%$ of $P_{g}$, on a ground area basis. Cumulative values of measured $\mathrm{P}_{g}$ and $I$ throughout the monitoring period are plotted in Fig. 2a.

Possible errors in throughfall due to wetting error, direct evaporation from the trough surfaces or to the effect of raindrops splashing into, or out of, the troughs were investigated by establishing a linear regression through the origin between rainfall collected by the trough $\left(P_{g, \text { trough }}\right)$ in the Open-plot and the corresponding rainfall measured by the
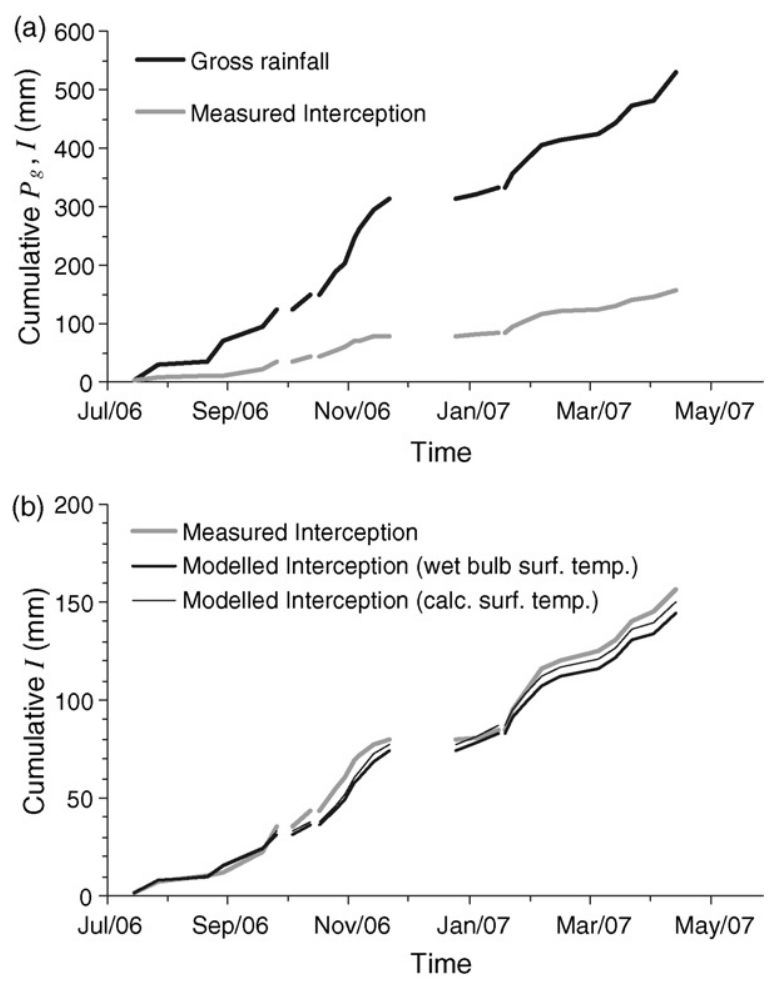

Fig. 2 - (a) Cumulative gross rainfall $\left(P_{g}\right)$ and observed interception loss (I) at the Mitra II site. (b) Cumulative observed and modelled interception loss. Modelled interception loss was calculated in two different ways: $\bar{E}_{c}$ calculated considering $T_{s, w}$ (black thick line) and $\bar{E}_{c}$ calculated considering $T_{s, \text { calc }}$ (black thin line).

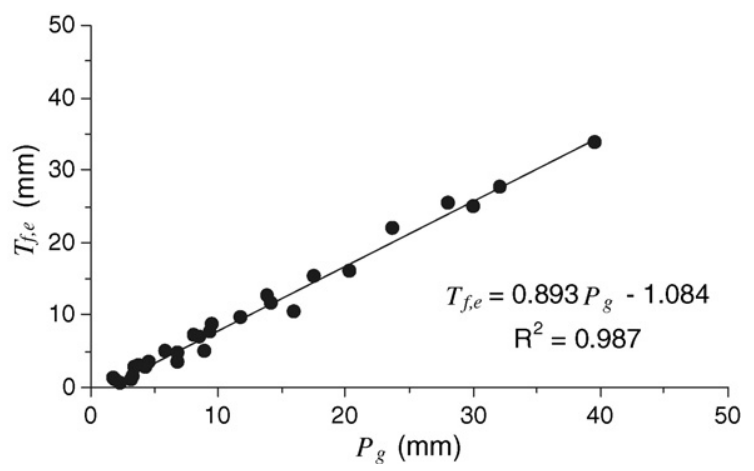

Fig. 3 - Equivalent throughfall $\left(T_{f, e}\right)$ plotted against gross rainfall for all the storms with $P_{g} \geq 1.5 \mathrm{~mm}$ recorded at Mitra I during 1996. Storage capacity was derived from the intercept of the regression line between these two variables.

funnel gauge $\left(P_{\text {g,gauge }}\right)$. The regression equation revealed a nearly one-to-one relationship $\left(P_{\text {g,trough }}=0.99 P_{\text {g,gauge }} ; R^{2}=0.99\right)$ showing that trough measurements were not affected by any of those errors. Wetting error and error resulting from direct evaporation were further checked by spraying the trough with a known volume of water, which was compared to the amount of water collected at the trough outlet. Again, these errors were less than $1 \%$.

\subsection{Model parameters}

$\overline{\mathrm{R}}$ estimates for Mitra II and Mitra I were 2.2 and $2.0 \mathrm{~mm} \mathrm{~h}^{-1}$, respectively. $\bar{E}_{c}$ estimated by Pereira et al. (2009) for Mitra II was $0.27 \mathrm{~mm} \mathrm{~h}^{-1}$, when the canopy surface temperature was taken equal to the wet bulb temperature $\left(\bar{E}_{c}\left(T_{s, w}\right)\right)$, but slightly higher when the surface temperature was calculated accounting for the available energy: $0.30 \mathrm{~mm} \mathrm{~h}^{-1}\left(\bar{E}_{c}\left(T_{s, \text { calc }}\right)\right)$. In Mitra II the rainfall interception model was applied with both these two estimates of $\bar{E}_{c}$, whereas in Mitra I it was only tested with $\bar{E}_{c}\left(T_{s, w}\right)$.

The linear regression $\left(T_{f, e}=0.893 P_{g}-1.08 ; R^{2}=0.99\right)$ established between equivalent throughfall and gross rainfall for all the storms of 1996 with $P_{g} \geq 1.5 \mathrm{~mm}$ from Mitra $I$ is represented in Fig. 3. The intercept of the regression line was used in Eq. (A14) (see Appendix A) to obtain an estimate for the tree storage capacity $\left(\mathrm{S}_{\mathrm{c}}\right): 1.16 \mathrm{~mm}$.

Following the methodology used by Link et al. (2004) adapted to the revised version of the Gash analytical model, an analysis of cumulative equivalent throughfall $\left(T_{f, e}\right)$ against cumulative $P_{g}$ was performed for a number of rainfall events selected from Mitra I data, as illustrated in Fig. 4 for two typical rainfall periods. This analysis shows that $\mathrm{T}_{f, e}$ only occurs after the accumulated rainfall exceeds an amount nearly identical to the rainfall necessary to saturate the canopy $\left(P_{g}^{\prime}\right)$ which was estimated according to the Gash analytical model as $1.25 \mathrm{~mm}$, i.e. throughfall only occurs after crown saturation is reached. This means that the assumption of complete cover $(c=1)$ at the crown level is correct, probably because the gaps in the crown are few and of small dimension. 

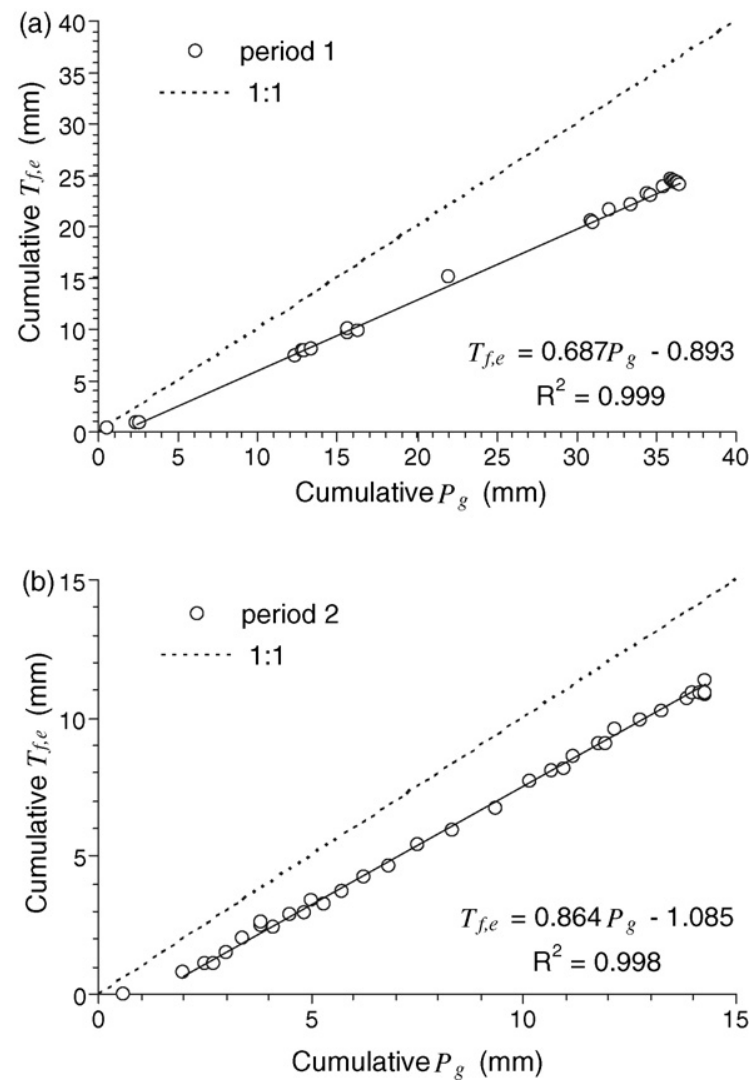

Fig. 4 - Cumulative equivalent throughfall $\left(T_{f, e}\right)$ plotted against the cumulative gross rainfall $\left(P_{g}\right)$ for two rainfall periods with different characteristics: (a) period 1: duration $=7.7 \mathrm{~h}$; rainfall amount $=\mathbf{3 6 . 4 8} \mathrm{mm}$; mean rainfall intensity $=4.7 \mathrm{~mm} \mathrm{~h}^{-1}$ (b) period 2: duration $=5.3 \mathrm{~h}$; rainfall amount $=14.27 \mathrm{~mm}$; mean rainfall intensity $=2.7 \mathrm{~mm} \mathrm{~h}^{-1}$.

\subsection{Modelling interception loss-Mitra II}

Results from the modelling of interception loss at Mitra II for the whole monitoring period are shown in Table 2, together with the evaluation of modelling performance. Estimated I, using either $\bar{E}_{c}\left(T_{s, w}\right)$ or $\bar{E}_{c}\left(T_{s, \text { calc }}\right)$, were similar to the observed values (Fig. 2b, Table 2), with differences between modelled and observed of $-7.8 \%$ or $-4.1 \%$ of $I$ when $\bar{E}_{c}\left(T_{s, w}\right)$ or $\bar{E}_{c}\left(T_{s, c a l c}\right)$ were used, respectively. Assuming a random measurement error of $\pm 2.5 \%$ in both $\mathrm{P}_{g}$ and $\mathrm{T}_{f}$ and summing these errors quadratically, an experimental error of $\pm 16.2 \mathrm{~mm}$ or $\pm 10.3 \%$ should be expected for I, greater than the differences found between model estimates and observations. Both model estimates are therefore within the likely experimental error.

\subsection{Modelling interception loss-Mitra I}

The model was also tested against an independent dataset obtained at the Mitra I site, but using only $\bar{E}_{c}\left(T_{s, w}\right)$. Since the 1996 data-subset was used to derive the value of $S_{c}$, the complementary data-subset (1997-1998) was used to test the interception model. Cumulative gross rainfall and observed interception loss for that period were 1394.6 and
Table 2 - Results of measured and modelled interception loss at both experimental sites.

\begin{tabular}{lcc} 
& $\begin{array}{c}\text { Mitra II } \\
(2006-2007)\end{array}$ & $\begin{array}{c}\text { Mitra I } \\
(1997-1998)\end{array}$ \\
\hline$P_{g}(\mathrm{~mm})$ & 528.7 & 1394.6 \\
$I(\mathrm{~mm})$ measured & 156.7 & 321.2 \\
I $\left(\% \mathrm{P}_{g}\right)$ measured & & \\
$\quad$ Tree crown projected area basis & 29.6 & 23.0 \\
$\quad$ Ground area basis & 6.2 & 9.0 \\
I (mm) modelled & & \\
$\quad$ Based on $\bar{E}_{c}\left(T_{s, w}\right)$ & 144.4 & 350.1 \\
$\quad$ Based on $\bar{E}_{c}\left(T_{s, \text { calc }}\right)$ & 150.3 & - \\
Expected error for measured & \pm 10.3 & \pm 13.7 \\
$\quad$ interception (\%) & & \\
Normalized averaged error (\%) & & \\
$\quad$ for modelled interception loss & & \\
$\quad$ Based on $\bar{E}_{c}\left(T_{s, w}\right)$ & -7.8 & +9.0 \\
$\quad$ Based on $\bar{E}_{c}\left(T_{s, \text { calc }}\right)$ & -4.1 & - \\
\hline
\end{tabular}

$321.2 \mathrm{~mm}$, respectively (Fig. 5, Table 2). I was thus $23 \%$ of $\mathrm{P}_{g}$ on a crown-projected area basis. Modelled interception loss was $350.1 \mathrm{~mm}$ (Fig. 5, Table 2), 9\% higher than the measured value. This difference is also within the expected error range for measured interception at this site (ca. $\pm 44 \mathrm{~mm}$ or $\pm 13.7 \%$ of I).

\section{Discussion}

Total interception loss at the Mitra II site, expressed on a crown area basis, was $156.7 \mathrm{~mm}$, representing $29.6 \%$ of $P_{g}$. This value is slightly higher than that found for the Mitra I site: $23 \%$ of $P_{g}$ over a 2-year period. This small difference may reflect the different rainfall conditions during the periods of measurement, differences between the tree samples, or may be the result of differences in the experimental setups used: (a) in Mitra I only one tree was monitored whereas in Mitra II our measurements were made on three different trees, (b) in Mitra II throughfall was measured by troughs with a sampling area significantly higher than that sampled by the funnel gauges used in Mitra I and (c) orientation of the radial sampling layout for throughfall was different at the two sites: North-South and East-West azimuths in Mitra I and Northeast-Southwest and Northwest-Southeast azimuths in Mitra II.

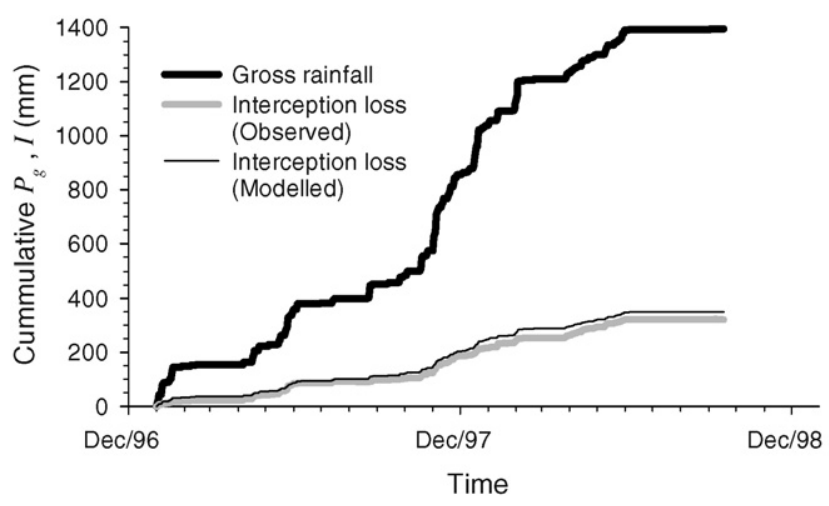

Fig. 5 - Cumulative gross rainfall $\left(P_{g}\right)$ and interception loss (I) at the Mitra I site. Both observed and modelled I are represented. 
As pointed out by David et al. (2006), not all of the interception studies made on isolated trees have been conducted appropriately, since they used procedures that only provide correct results for close-to-vertical rainfall events. Therefore, when comparing results from different studies we should be aware of possible errors in the observations. Nevertheless, the interception loss on a crown area basis measured at Mitra II $\left(29.6 \%\right.$ of $\left.P_{g}\right)$ is similar to that observed in other isolated Mediterranean trees: $27 \%$ of $\mathrm{P}_{g}$ in a Q. suber tree in California (Xiao et al., 2000), 21.7\% of $P_{g}$ in five individual olive trees in Southern Spain (Gómez et al., 2001), and $26.8 \%$ of $P_{g}$ in four $Q$. ilex trees in a Spanish dehesa in the Guadalperalón catchment (Mateos, 2003). In this latter study, Mateos (2003) subjected two of the studied trees to a commonly used pruning practice, and kept the other two trees unpruned. Interception loss varied between $23.6 \%$ and $29.9 \%$ of $P_{g}$ in pruned and unpruned trees, respectively. These values are comparable to our results at Mitra II.

On a ground area basis, interception loss from savannas and dry woodlands is usually small due to the low tree density and crown cover fraction. Reported values vary from $4 \%$ of $\mathrm{P}_{g}$ in a holm oak dehesa in Spain (Mateos, 2003), 8\% of $P_{g}$ in an olive tree orchard in Southern Spain (Gómez et al., 2001) and 10\% of $\mathrm{P}_{g}$ in an agroforestry stand in Kenya (Jackson, 2000). In the Mitra I site, interception loss on a ground area basis was $9 \%$ of $P_{g}$ (David et al., 2006), which is slightly higher than that observed at Mitra II (6.2\% of $\left.P_{g}\right)$. This difference is a consequence of the distinct crown cover fractions in the two sites: $39 \%$ in Mitra I and 21\% in Mitra II. Interception loss on a ground area basis at the two Mitra sites is in the lower range of observed values (see David et al., 2005). Nevertheless, its impact on the scarce water resources of Mediterranean regions should not be neglected. Denser Mediterranean forests usually show higher interception loss ratios. For instance, Valente et al. (1997) report interception loss values of $11.8 \%$ and $17 \%$ of $P_{g}$ for Mediterranean Eucalyptus globulus and Pinus pinaster plantations, with canopy cover fractions of 0.60 and 0.64 , respectively.

In contrast to $\bar{E}_{c}, \bar{R}$ does vary significantly with climate type (e.g. Lloyd et al., 1988; Pearce and Rowe, 1981), with tropical regions dominated by convective rainfall showing higher mean rainfall rates than temperate ones, where the rain is generated by larger scale synoptic features. In Mediterranean climates, the rainfall regime is a mixture of tropical and temperate features (David et al., 2006). $\bar{R}$ values derived for the Mitra II and Mitra I sites were 2.2 and $2.0 \mathrm{~mm} \mathrm{~h}^{-1}$, respectively. These rates lie in the range of observed values in other studies under Mediterranean climate: $2.3-2.5 \mathrm{~mm} \mathrm{~h}^{-1}$ for two deciduous forests in Slovenia (Sraj et al., 2008), 1.7 and $1.8 \mathrm{~mm} \mathrm{~h}^{-1}$ for two stands of pine and eucalypt in Portugal, respectively (Valente et al., 1997) and $3.8 \mathrm{~mm} \mathrm{~h}^{-1}$ for a pine forest in a mountainous area of Spain (Llorens et al., 1997). For an agroforestry system in a semi-arid area in Kenya, Jackson (2000) also observed a similar mean rainfall rate: $2.3 \mathrm{~mm} \mathrm{~h}^{-1}$.

The revised version of Gash's analytical model performed well when used at the individual tree level to estimate interception loss at the Mitra II site, with model estimates being within the likely error bands of the observations. As expected, when the surface temperature was taken to be equal to the wet bulb temperature, the $\bar{E}_{c}$ value $\left(0.27 \mathrm{~mm} \mathrm{~h}^{-1}\right)$ was slightly lower than that calculated accounting for the available energy $\left(0.30 \mathrm{~mm} \mathrm{~h}^{-1}\right)$. Fig. $2 \mathrm{~b}$ shows that this difference in $\bar{E}_{c}$ translates into a difference in estimated interception loss of about $4 \%$ of the measured value at Mitra II (see also Table 2). However, the difference between the two interception loss estimates is less than the expected measurement error, which is unlikely to be lower than approximately $\pm 16 \mathrm{~mm}$. Therefore, there is little justification for using the more complex and data-demanding method based on the calculation of surface temperature.

We believe that the much simpler method of assuming surface temperature equal to the wet bulb temperature should be preferred. The application of Gash's analytical model to the independent dataset of Mitra I (David et al., 2006) acts as a demonstration of this philosophy. Again, there is good agreement between measured and modelled interception loss, under the assumption that the leaves are at the wet bulb temperature (Fig. 5). Total modelled interception loss was $9 \%$ higher than observation, but the difference $(28.93 \mathrm{~mm})$ is smaller than the expected measurement error (estimated as not better than $\pm 44 \mathrm{~mm}$ ).

Finally, it should be noted that the proposed modelling approach, based on the use of $\bar{E}_{c}\left(T_{s, w}\right)$, will not be appropriate if combined with a running water balance model for interception loss, such as the Rutter model. For this model-type, and whenever crowns are not fully saturated, surface temperature will deviate from $T_{w}$ and actual evaporation rate will tend to be higher than $\bar{E}_{c}\left(T_{s, w}\right)$.

\section{Concluding remarks}

In a complementary study, Pereira et al. (2009) suggested that evaporation from wet, isolated trees could be accurately estimated by assuming that the leaf temperature equals the wet bulb temperature of the surrounding air. The results presented here validate that hypothesis, demonstrating that the saturated crowns of isolated trees act as wet bulbs. A treebased modelling approach based on this assumption performed well in estimating the interception loss from two widely spaced savanna-type oak woodlands. The model is also physically based and requires a limited amount of data. For its practical application we only need to know: the dry and wet bulb air temperatures, windspeed, leaf dimensions, leaf area index (for individual trees) and crown storage capacity. To scale up observations to the stand level, the crown cover fraction is also needed. The tree-based modelling approach proposed here is the first, to our knowledge, to model interception loss from individual trees by adapting an interception model originally meant for closed forests. It should be suitable for modelling the evaporation of intercepted rainfall from isolated trees or savanna-type ecosystems that occur in vast areas of the globe and where water issues are often problematic.

\section{Acknowledgements}

The authors thank the University of Évora for permission to work at the "Herdade da Mitra" field site. This study was 
supported by research project SAPIENS/FCT No. POCTI/AGG/ 39220/2001 funded by the Fundação para a Ciência e Tecnologia. Funding was also provided by the Conselho de Reitores das Universidades Portuguesas and the British Council under the Treaty of Windsor Programme 2007/08-U27.

\section{Appendix A. A new procedure for estimating canopy storage capacity according to the revised version of the Gash analytical model}

For a sparse forest and according to the revised versions of the Rutter and the Gash models (Valente et al., 1997), for any storm that completely saturates the canopy, throughfall $\left(T_{f}\right)$ can be expressed on a whole plot area basis as

$\mathrm{T}_{f}=\left(1-c p_{d}\right) P_{g}-\left(1-p_{d}\right) S-c\left(1-p_{d}\right) \int E_{c} d t$

Eq. (A1) can be taken as the basis of a procedure to determine S, following the admission that a linear relationship exists between $I$ and $P_{g}$ (Gash, 1979). Whenever drainage from the canopy into the trunks is very small $\left(p_{d} \approx 0\right)$, stemflow will be negligible and interception can then be taken as the difference $I=P_{g}-T_{f}$, a linear relationship between $T_{f}$ and $P_{g}$ can then also be assumed:

$\mathrm{T}_{f}=a \mathrm{P}_{g}+b$

For storms large enough to saturate the canopy and following Gash (1979), evaporation from the canopy during rainfall can be separated into two components: evaporation during the period of unsaturated canopy, from the beginning of rainfall $(t=0)$ until canopy saturation is reached $\left(t=t^{\prime}\right)$, and evaporation from the saturated canopy until the end of rainfall (time interval $\left[t^{\prime}, t\right]$ ). Accordingly, Eq. (A1) can then be expanded to

$\mathrm{T}_{f}=\mathrm{P}_{g}-c \int_{0}^{\mathrm{t}^{\prime}} E_{c} \mathrm{dt}-c \int_{t}^{t} E_{c} \mathrm{dt}-\mathrm{S}$

Following Gash (1979), the mean evaporation rate from the saturated canopy during rainfall $\left(\bar{E}_{c}\right)$ can be defined as

$\bar{E}_{c}=\frac{\int_{t^{\prime}}^{t} E_{c} d t}{\left(t-t^{\prime}\right)}$

and a mean rainfall rate $(\bar{R})$ can also be defined as

$\bar{R}=\frac{\int_{t^{\prime}}^{t} P_{g} d t}{\left(t-t^{\prime}\right)}$

giving

$\frac{\left(P_{g}-P_{g}^{\prime}\right)}{\bar{R}}=\left(t-t^{\prime}\right)$

where $P_{g}^{\prime}$ represents the amount of rain necessary to saturate the canopy. Substituting Eqs. (A4)-(A6) into Eq. (A3) and rearranging we obtain

$\mathrm{T}_{f}=\left[1-c \overline{\overline{E_{c}}} \overline{\bar{R}}\right] P_{g}-S+c \frac{\overline{E_{c}}}{\bar{R}} P_{g}^{\prime}-c \int_{0}^{t^{\prime}} E_{c} d t$
Assuming as Gash (1979) that dripping from the canopy will only occur after the canopy is saturated, the amount of rainfall needed to reach saturation is

$P_{g}^{\prime}=\frac{S}{c}+\int_{0}^{t^{\prime}} E_{c} d t$

Accordingly, Eq. (A7) can be rearranged to

$T f=\left(1-c \frac{\overline{E_{c}}}{\bar{R}}\right) P_{g}+\left[\frac{\overline{E_{c}}}{\bar{R}} S+c\left(\frac{\overline{E_{c}}}{\bar{R}}-1\right) \int_{0}^{t^{\prime}} E_{c} d t-S\right]$

Equating coefficients of a regression between measured $\mathrm{T}_{f}$ and $\mathrm{P}_{g}$ (see Eq. (A2)) gives

$a=\left(1-c \frac{\overline{E_{c}}}{\bar{R}}\right)$

$b=\frac{\overline{E_{c}}}{\bar{R}} S+c\left(\frac{\overline{E_{c}}}{\bar{R}}-1\right) \int_{0}^{t^{\prime}} E_{c} d t-S$

and from Eq. (A8) the storage parameter $\mathrm{S}$ can be determined as

$S=\frac{b}{\left(\left(\bar{E}_{c} / \bar{R}\right)-1\right)}-c \int_{0}^{t^{\prime}} E_{c} d t$

The integral in Eq. (A9) represents evaporation from the unsaturated canopy during the wetting phase. Since it is assumed that evaporation from the canopy during this phase is reduced in proportion to the ratio between the amount of water retained by the canopy at a given moment before saturation is reached $\left(C_{c}\right)$ and the canopy storage capacity $\left(S_{c}\right)$ (Rutter et al., 1971) and under the additional assumption that in the wetting phase mean evaporation and rainfall rates also apply (Gash, 1979), evaporation during this phase can then be given by

$E_{c}=\frac{C_{c}}{S_{c}} \bar{E}_{c}$

and the integral above may be written as

$\int_{0}^{t^{\prime}} E_{c} d t=\int_{0}^{t^{\prime}} \frac{\bar{E}_{c}}{S_{c}} C_{c} d t=\frac{\bar{E}_{c}}{S_{c}} \int_{0}^{t^{\prime}} C_{c} d t$

Following Rutter et al. (1971), the rate of change of water stored in the canopy before it becomes saturated is

$\frac{d C_{c}}{d t}=\bar{R}-\bar{E}_{c} \frac{C_{c}}{S_{c}}$

Using Eq. (A11) to change variables in the last integral of Eq. (A10) and considering that at the beginning of a storm the canopy is $\operatorname{dry}\left(C_{c}(0)=0\right)$ and at time $t^{\prime}$ it becomes saturated $\left(C_{c}\left(t^{\prime}\right)=S_{c}\right)$, one obtains

$\int_{0}^{t^{\prime}} C_{c} d t=\int_{0}^{S_{c}} C_{c} \frac{1}{\bar{R}-\bar{E}_{c}\left(C_{c} / S_{c}\right)} d C_{c}$

This new integral can now be easily solved as

$\int_{0}^{t^{\prime}} C_{c} d t=-\frac{S_{c}}{\bar{E}_{c}}\left[S_{c}+\frac{\bar{R}}{\bar{E}_{c}} S_{c} \ln \left(1-\frac{\bar{E}_{c}}{\bar{R}}\right)\right]$ 
Substituting Eqs. (A13) and (A10) into Eq. (A9), allows the canopy storage capacity to be calculated as

$S=-\frac{b}{\left(\left(\bar{E}_{c} / \bar{R}\right)-1\right)} \frac{\bar{E}_{c}}{\bar{R}} \frac{1}{\ln \left(1-\left(\bar{E}_{c} / \bar{R}\right)\right)}$

\section{R E F E REN C E S}

Asdak, C., Jarvis, P.G., Gardingen, P.V., 1998. Modelling rainfall interception in unlogged and logged forest areas of Central Kalimantan, Indonesia. Hydrology and Earth System Sciences 2 (2-3), 211-220.

Carreiras, J.M.B., Pereira, J.M.C., Pereira, J.S., 2006. Estimation of tree canopy cover in evergreen oak woodlands using remote sensing. Forest Ecology and Management 223, 45-53.

David, J.S., Valente, F., Gash, J.H.C., 2005. Evaporation of intercepted rainfall. In: Anderson, M.G. (Ed.), Encyclopedia of Hydrological Sciences. John Wiley \& Sons. Ltd., Chichester, UK, (Chapter 43), pp. 627-634.

David, T.S., Gash, J.H.C., Valente, F., Pereira, J.S., Ferreira, M.I., David, J.S., 2006. Rainfall interception by an isolated evergreen oak tree in a Mediterranean savannah. Hydrological Processes 20 (13), 2713-2726.

DGRF, 2007. Resultados do Inventário Florestal Nacional 20052006. Direcção-Geral dos Recursos Florestais, Lisboa. http:// www.dgrf.min-agricultura.pt/portal/politica-e-planeamento -florestal/infor-florestal/ifn-apresentacao-de-resultados.

Gash, J.H.C., 1979. An analytical model of rainfall interception by forests. Quarterly Journal of the Royal Meteorological Society 105, 43-55.

Gash, J.H.C., Shuttleworth, W.J. (Eds.), 2007. Evaporation, Benchmark Papers in Hydrology, vol. 2. IAHS Press, Wallingford, pp. 521.

Gash, J.H.C., Lloyd, C.R., Lachaud, G., 1995. Estimating sparse forest rainfall interception with an analytical model. Journal of Hydrology 170, 79-86.

Gómez, J.A., Giraldez, J.V., Fereres, E., 2001. Rainfall interception by olive trees in relation to leaf area. Agricultural Water Management 49 (1), 65-76.

Horton, R.E., 1919. Rainfall interception. In: Gash, J.H.C., Shuttleworth, W.J. (Eds.), Evaporation, Benchmark Papers in Hydrology. IAHS Press, Wallingford, pp. 121-141.

Hutjes, R.W.A., Wierda, A., Veen, A.W.L., 1990. Rainfall interception in the Tai Forest, Ivory Coast: application of two simulation models to a humid tropical system. Journal of Hydrology 114 (3-4), 259-275.

Jackson, N.A., 2000. Measured and modelled rainfall interception loss from an agroforestry system in Kenya. Agricultural and Forest Meteorology 100, 323-336.

Klaassen, W., Bosveld, F., de Water, E., 1998. Water storage and evaporation as constituents of rainfall interception. Journal of Hydrology 212-213, 36-50.
Leyton, L., Reynolds, E.R.C., Thompson, F.B., 1967. Rainfall interception in forest and moorland. In: Sopper, W.E., Lull, H.W. (Eds.), International Symposium on Forest Hydrology. Proceedings of a National Science Foundation Advanced Science Seminar Held at The Pennsylvania State University, Pennsylvania, August 29, September 10, 1965. Pergamon Press, Oxford, New York, pp. 163-178.

Link, T.E., Unsworth, M., Marks, D., 2004. The dynamics of rainfall interception by a seasonal temperate rainforest. Agricultural and Forest Meteorology 124 (3-4), 171-191.

Llorens, P., Poch, R., Latron, J., Gallart, F., 1997. Rainfall interception by a Pinus sylvestris forest patch overgrown in a Mediterranean mountainous abandoned area. I. Monotoring design and results down to the event scale. Journal of Hydrology 199, 331-345.

Lloyd, C.R., Gash, J.H.C., Shuttleworth, W.J., de O. Marques, F.A., 1988. The measurement and modelling of rainfall interception by Amazonian rain forest. Agricultural and Forest Meteorology 43 (3-4), 277-294.

Mateos, B., 2003. Interceptación de la lluvia por la encina en espacios adehesados. Universidad de Extremadura, Cáceres, Spain, pp. 152.

Pearce, A.J., Rowe, L.K., 1981. Rainfall interception in a multi-storied, evergreen mixed forest-estimates using Gash analytical model. Journal of Hydrology 49 (3-4), 341-353.

Pereira, J.S., Mateus, J.A., Aires, L.M., Pita, G., Pio, C., David, J.S., Andrade, V., Banza, J., David, T.S., Paço, T.A., Rodrigues, A., 2007. Net ecosystem carbon exchange in three contrasting Mediterranean ecosystems-the effect of drought. Biogeosciences 4 (5), 791-802.

Pereira, F.L., Gash, J.H.C., David, J.S., Valente, F., 2009. Evaporation of intercepted rainfall from isolated evergreen oak trees. Do the crowns behave as wet bulbs? Agricultural and Forest Meteorology 149, 680-688.

Rutter, A.J., Robins, P.C., Morton, A.J., Kershaw, K.A., 1971. A predictive model of rainfall interception in forests. 1. Derivation of the model from observations in a plantation of Corsican Pine. Agricultural Meteorology 9, 367-384.

Schellekens, J., Scatena, F.N., Bruijnzeel, L.A., Wickel, A.J., 1999. Modelling rainfall interception by a lowland tropical rain forest in northeastern Puerto Rico. Journal of Hydrology 225, 168-184.

Sraj, M., Brilly, M., Mikos, M., 2008. Rainfall interception by two deciduous Mediterranean forests of contrasting stature in Slovenia. Agricultural and Forest Meteorology 148 (1), 121134.

Valente, F., David, J.S., Gash, J.H.C., 1997. Modelling interception loss for two sparse eucalypt and pine forests in central Portugal using reformulated Rutter and Gash analytical models. Journal of Hydrology 190, 141-162.

Xiao, Q., McPherson, E.G., Ustin, S.L., Grismer, M.E., Simpson, J.R., 2000. Winter rainfall interception by two mature opengrown trees in Davis, California. Hydrological Processes 14, 763-784. 